\title{
Characteristics of Earthquake-Generated Tsunamis in Indonesia Based on Source Parameter Analysis
}

\author{
Sugeng Pribadi ${ }^{1,2}$, Afnimar ${ }^{3}$, Nanang T. Puspito ${ }^{3}$ \& Gunawan Ibrahim ${ }^{3}$ \\ ${ }^{1}$ Tsunami Warning Information Division Indonesian, Meteorological Climatological and \\ Geophysical Agency (BMKG), Jalan Angkasa I No. 2, Jakarta13920, Indonesia \\ ${ }^{2}$ Graduate Student of Earth Sciences, Faculty of Earth Sciences and Technology, Institut \\ Teknologi Bandung, Jalan Ganesha No. 10, Bandung 40132, Indonesia \\ ${ }^{3}$ Global Geophysics Research Group, Faculty of Mining and Petroleum Engineering, \\ Institut Teknologi Bandung, Jalan Ganesha No. 10, Bandung 40132, Indonesia \\ Email: sugengpribadimsc@gmail.com
}

\begin{abstract}
We have characterized 27 earthquake-generated tsunamis from 1991 to 2012 in Indonesia, based on source parameter analysis. This includes the focal mechanism derived by $\mathrm{W}$ phase inversion analysis, the ratio $(\Theta)$ between the seismic energy $(E)$ and the seismic moment $\left(M_{o}\right)$, the moment magnitude $\left(M_{w}\right)$, the rupture duration (To) and the distance of the hypocenter to the trench. Most of the earthquakes ( 24 events) were tsunamigenic earthquakes with various fault types, a shallow focal depth $(12 \mathrm{~km} \leq D \leq 77.8 \mathrm{~km})$, a small to large magnitude $\left(6.6 \leq M_{w} \leq 9.0\right)$, a low ratio of seismic energy to seismic moment $(-5.8<\Theta<-$ 4.9), a short to long rupture duration ( $27 \mathrm{~s} \leq T o \leq 257 \mathrm{~s}$ ), a small to large tsunami height $(0.1 \mathrm{~m} \leq H \leq 50.9 \mathrm{~m})$ and a short to long distance from the hypocenter to the trench $(10 \mathrm{~km}<H T \leq 230 \mathrm{~km})$. Three tsunami earthquakes were characterized by a thrust fault mechanism, a very shallow depth $(D \leq 20 \mathrm{~km})$, a moderate magnitude $\left(7.5 \leq M_{w} \leq 7.8\right)$, a very low ratio of seismic energy to seismic moment $(\Theta \leq-5.8)$, a long rupture duration ( $99 \mathrm{~s} \leq T o \leq 135 \mathrm{~s}$ ), a large tsunami height $(7.4 \mathrm{~m} \leq H \leq 14 \mathrm{~m})$ and a short distance from the hypocenter to the trench $(H T \leq 20 \mathrm{~km})$.
\end{abstract}

Keywords: characteristics; moment; rupture; tsunamigenic earthquake; tsunami earthquake; W phase; energy.

\section{Introduction}

About $90 \%$ of the tsunamis that have occurred in the Indonesia region were generated by earthquakes, with a variety of focal mechanisms and hypocenter depths $[1,2]$. In the sea regions of Sumatra, the Andaman Islands, Java, Sumba and Molucca, most commonly thrust fault mechanisms occurred. Some earthquake-generated tsunamis in the Makassar strait were caused by normal faults. Strike-slip fault mechanisms occurred in several areas of the Banda Sea. The Papua earthquake-generated tsunamis occurred as a result of thrust faults and strike-slip faults. The December 26, 2004 Aceh earthquake was purely thrust fault, with a large magnitude $\left(M_{w}=9.1\right)$ and a very large extending

Received April $3^{\text {rd }}, 2013,1^{\text {st }}$ Revision July $17^{\text {th }}, 2013,2^{\text {nd }}$ Revision July $26^{\text {th }}, 2013$, Accepted for publication July $29^{\text {th }}, 2013$.

Copyright $\odot 2013$ Published by ITB Journal Publisher,ISSN: 2337-5760, DOI: 10.5614/j.math.fund.sci.2013.45.2.8 
rupture $(1300 \mathrm{~km})$ [3-5]. The July 17, 2006 Java earthquake involved thrust fault in the Java trench with a medium magnitude $\left(M_{w}=7.8\right)$ [6]. This was an inter-plate earthquake located at a very shallow depth [6]. Latief, et al. [1] made a catalog of tsunamis and subduction zones in Indonesia over the period of 1800 to 1999 using statistic analysis with frequency and damage criteria. However, the characteristics of the earthquake-generated tsunamis that have occurred over the last two decades in Indonesia have not been studied very well. Especially the characteristics of tsunamigenic earthquakes and tsunami earthquakes are still not well understood.

Satake and Tanioka [7] classify earthquakes that generate tsunamis anywhere in the world into: inter-plate earthquakes, intra-plate earthquakes and tsunami earthquakes, based on the hypocenter position in the subduction zone relative to the trench. A common earthquake that generates a tsunami is called a tsunamigenic earthquake. However, a special type of earthquakes with unique characterizations are referred to as tsunami earthquakes. Tsunami earthquakes are characterized by a long rupture duration, a lower body wave magnitude and location of the epicenter near the trench [8,9]. Kanamori [10] has characterized the September 2, 1992 Nicaragua earthquake as a tsunami earthquake using the W phase method. Kanamori and Rivera [11] have analyzed the December 26, 2004 Sumatra earthquake, the July 17, 2006 Java earthquake and the September 12, 2007 Sumatra earthquake with the same method. For the purpose of tsunami modeling, Handayani [12] employed a method similar to the one used by Kanamori and Rivera [11] to characterize earthquakes that have generated tsunamis in Indonesia from 2004 to 2009. Newman and Okal [13] investigated the ratio $(\Theta)$ between seismic energy $(E)$ and seismic moment $\left(M_{\mathrm{o}}\right)$ to identify 52 large earthquakes from 1982 to 1997 with data taken from the catalog of the National Earthquake Information Center (NEIC), provided by 500 teleseismic stations. Their study covers earthquakes in Indonesia, such as the December 12, 1992 Flores earthquake, the June 2, 1994 Java earthquake, the January 1, 1996 Minahasa earthquake and the February 17, 1996 Papua earthquake. Polet and Kanamori [14] employed the ratio $(\Theta)$ between seismic energy $(E)$ and seismic moment $\left(M_{o}\right)$ to investigate large-scale earthquakes. Lomax, et al. [15] used the same method as two previous studies [13,14] and defined tsunami earthquakes by ratio $\Theta<-5.5$. Newman, et al. [16] have analyzed the rupture duration of the October 25, 2010 Sumatra earthquake and categorized it as a specific tsunami earthquake.

The aim of this study was to characterize earthquake-generated tsunamis in the Indonesia region based on the focal mechanism, the ratio $(\Theta)$ between seismic energy $(E)$ and seismic moment $\left(M_{o}\right)$, the moment magnitude $\left(M_{w}\right)$, the rupture duration (To) and the distance of the hypocenter to the trench $(H T)$. We hope that the results of this study will contribute to better tsunami hazard zoning in 
the Indonesia region. In addition, we hope that in the near future the results of this study will support the work of the Indonesian Tsunami Early Warning System (Ina-TEWS).

\section{Data}

This study utilized the tsunami and earthquake data catalog of the National Oceanic and Atmospheric Administration (NOAA, http://www.ngdc.noaa.gov), Tsunami Laboratory Russia (http://tsun.sscc.ru) and the Global Centroid Moment Tensor Project (Global CMT, www.globalcmt.org/CMTsearch.html). Moreover, the hypocenter data relocated by Engdahl, et al. [17] were used. The seismic waveforms were obtained from IRIS (Incorporated Research Institutions for Seismology, www.iris.edu/cgi-bin/wilberII/wilberII_page1.pl). The databases and seismic waveforms were re-accessed on February 7, 2012. This study has collected 27 earthquake-generated tsunamis around Indonesia from 1991 to 2012 with a magnitude $M_{w}>6.5$ and shallow depth $(D \leq 77.8$ $\mathrm{km})$, as listed in Table 1. The geographical coordinates of the studied area are longitude $90^{\circ} \mathrm{E}-140^{\circ} \mathrm{E}$ and latitude $15^{\circ} \mathrm{S}-8^{\circ} \mathrm{N}$, as shown in Figure 1.

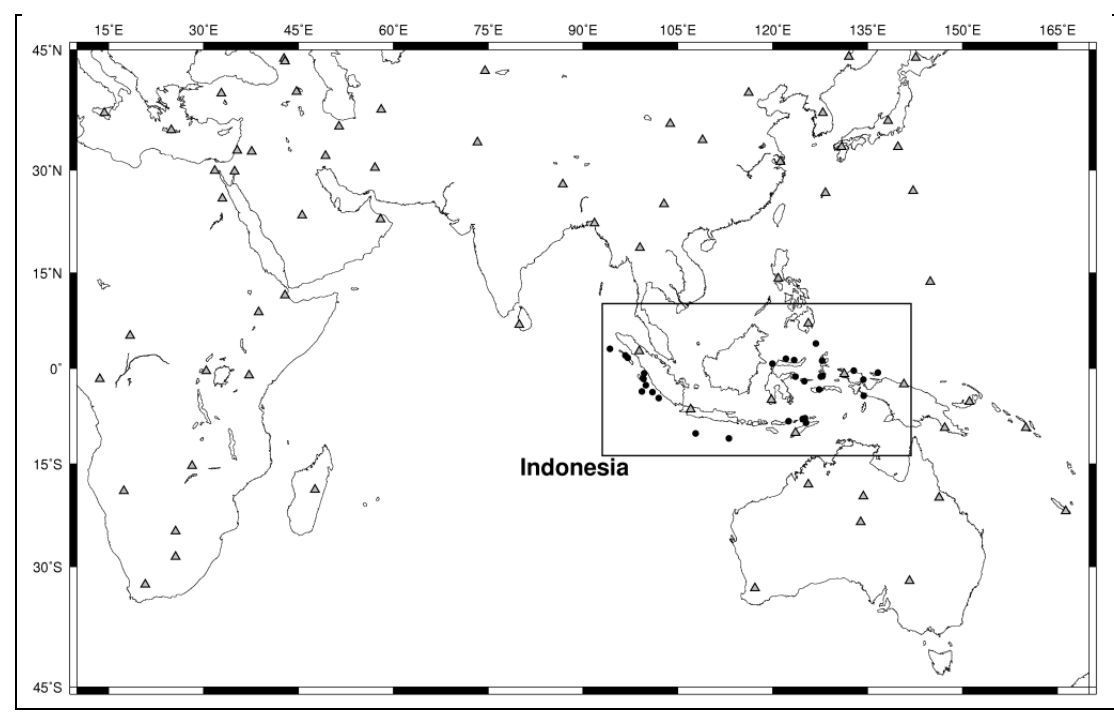

Figure 1 Global IRIS station network and study area. Stations shown as gray triangles, earthquake-generated tsunamis as black dots, and study area as a rectangle. 


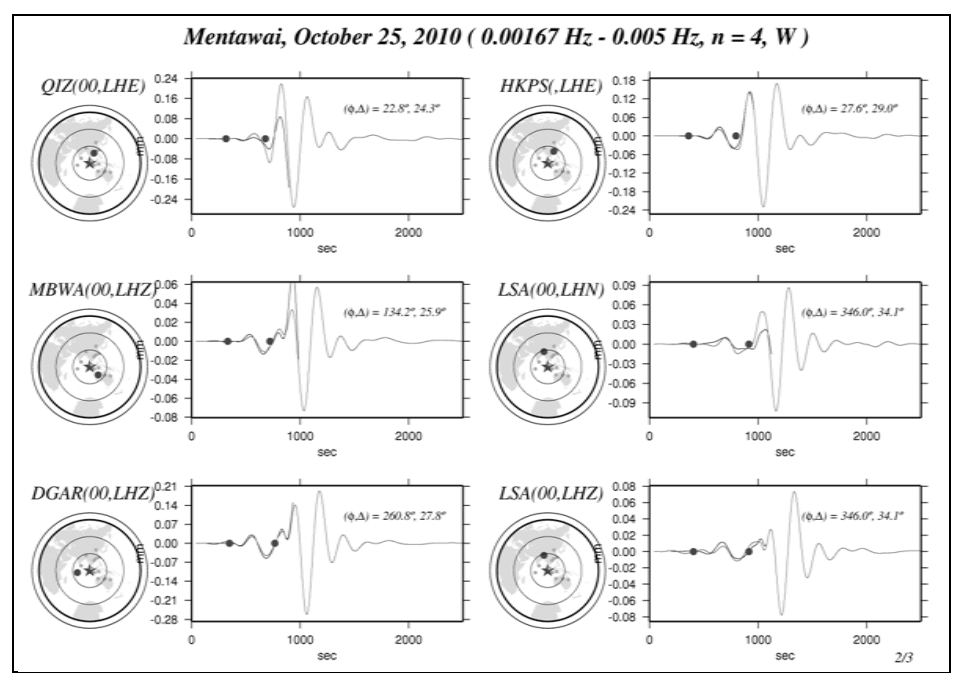

Figure 2 Waveform fitting between synthetic and observed signals for the October 25, 2010 Sumatra earthquake. The global spheres on the left show the distribution of the observation stations (grey dots), the recording observation stations (black dot), and the epicenter (black star). The graphs show the synthetic $\mathrm{W}$ phase signals (thick lines) and the observed signals (thin lines).

\section{W phase Method}

The $\mathrm{W}$ phase method is an alternative, faster inversion analysis, nearly identical to the Global CMT solution. The $\mathrm{W}$ phase is a long-period wave phase $(T>100$ s), whose propagation is similar to that of whispering gallery waves. It consists of a group of $P$ and $S$ waves $(P, P P, S S, S P, P S$ and $S$ ). The W phase clearly distinguishes an earthquake with a great magnitude from teleseismic body waves. The average length of the wave signal was used to detect the September 2, 1992 Nicaragua tsunami earthquake [10]. In addition, W phase analysis produces the focal mechanism, the focal depth, the hypocenter location, the seismic moment and the moment magnitude, which follows the double couple principle using the least-squares method. The $\mathrm{W}$ phase can be simulated by the summation of the normal fundamental modes of the $1^{\text {st }}, 2^{\text {nd }}$ and $3^{\text {rd }}$ overtone. The input data processing of $\mathrm{W}$ phase uses formatting and moment tensor inversion performed by Global CMT or value estimation for earthquakes that generate tsunamis. For detailed information about the wave-theory and modeling of W phase we refer to Kanamori and Rivera [11].

For example, $\mathrm{W}$ phase inversion presents the source point according to the origin time of the Global CMT (centroid location), as shown in Figure 2 for the 
October 25, 2010 Sumatra earthquake. The synthetic signals (thick lines) of the $\mathrm{W}$ phase are indicated by two parallel black dots coinciding with the observed signals (thin lines). All distribution stations are marked by grey dots, the selected stations by black dots, and the epicenters by black stars. The total number of IRIS stations used in this study was 912, equipped with long-period seismometers (LHZ, LHE, LHN). The stations' azimuths cover the whole planet Earth from $0^{\circ}-360^{\circ}$. The distance between seismometer and earthquake ranged from $11^{\circ}-90^{\circ}$. The frequency range $(0.005 \mathrm{~Hz}-0.02 \mathrm{~Hz})$ of the long-period wave depends on the earthquake magnitude [18].

\section{$4 \quad$ Ratio of Seismic Energy and Moment}

The seismic moment describes the overall size of the earthquake deformation $[19,20]$. The moment magnitude is the scale of the seismic moment [16]. Data on the waveforms were collected from 783 vertical component broadband sensors of IRIS. These waveforms were analyzed by the $P$ phase of the body waves recorded by a teleseismic station at a distance of more than $30^{\circ}$. In this study, the velocity seismogram was converted to displacement by applying the formula of Lomax, et al. [15], where the Butterworth bandpass filters were obtained from $0.001 \mathrm{~Hz}-5 \mathrm{~Hz}$. The signal processing of seismic energy can be seen in Figure 3.

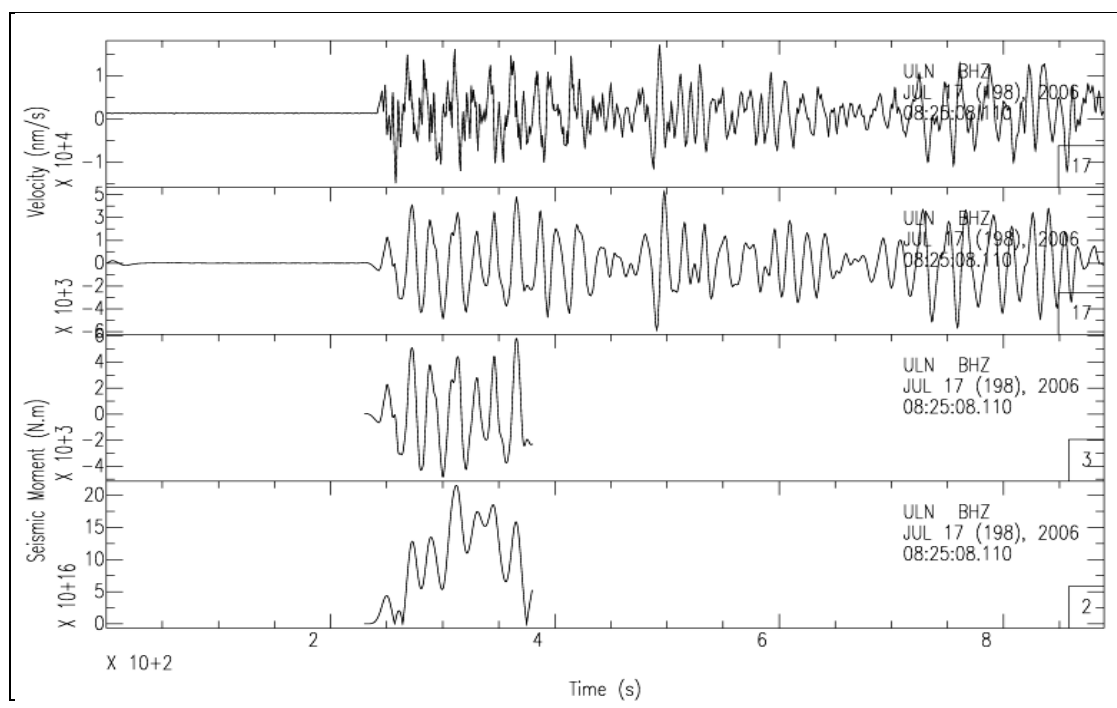

Figure 3 The July 17, 2006 Java earthquake was recorded by ULN station. The signal processing from top to bottom: ground velocity signal $\left(\mathrm{nm} . \mathrm{s}^{-1}\right)$, removing instrument response and filtering, cutting, and seismic moment (N.m). 


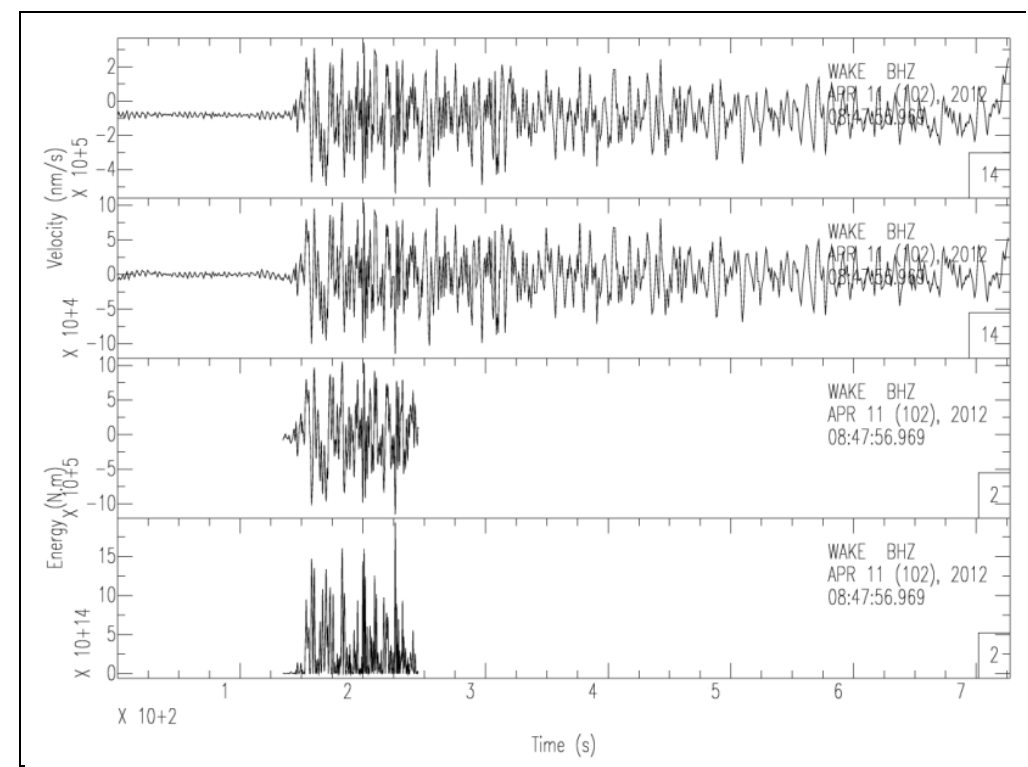

Figure 4 Seismogram of WAKE station detecting the April 11, 2012 Sumatra earthquake. From top to bottom: velocity signal $\left(\mathrm{nm} . \mathrm{s}^{-1}\right)$, removing instrument response and filtering, squaring, and seismic energy.

The equations of seismic moment $\left(M_{o}\right)$ and moment magnitude $\left(M_{w}\right)$ were derived from Kanamori [20] and Tsuboi, et al. [21], as shown below:

$$
\begin{aligned}
& M_{o}=\left|\max \left(\int u_{z}\left(x_{r}, t\right) d t\right)\right| .4 \pi \rho^{3} r \\
& M_{w}=\left(\frac{\log M_{o}-9.1}{1.5}\right)
\end{aligned}
$$

where,

$$
\begin{array}{ll}
u_{z}\left(x_{r}, t\right) & =\text { displacement }\left(10^{-2} \mathrm{~m}\right) \\
\rho & =\text { material density }\left(3.4 \times 10^{3} \mathrm{~kg} \cdot \mathrm{m}^{-3}\right) \\
r & =\text { distance from source to station }\left(10^{3} \mathrm{~m}\right) .
\end{array}
$$

Moment calculation was started by cutting the ground motion velocity signal, as the raw input data, of the $P-P P$ phase. The $P$ phase propagates directly from the source to the receiver. The $P P$ phase is then reflected to the earth's surface before it reaches the sensor. Cutting the $P-P P$ signal was applied in order to eliminate other propagation effects that inhibit the calculation of moment. The onset time of the wave phase was determined by the Tau-P program with the IASP91 velocity model [22] and refers to Jeffery Bullens [23]. For signal 
processing, the Seismic Analysis Code (SAC) program was used [24]. The instrument response of each seismometer was removed by transfer function. The frequency range of the Butterworth band-pass filter was obtained between $0.001 \mathrm{~Hz}-5 \mathrm{~Hz}$, which was determined by the frequency spectrum. Then, the signal was tapered in order to render it symmetric between the end point and the starting point of the seismic waveform. The velocity signal was integrated to get the displacement signal, whose value is equivalent to the moment rate. Furthermore, the second integral function and the formula of Tsuboi, et al. [21] were applied in order to calculate the seismic moment $\left(M_{o}\right)$. For example, the processing signal for the July 17,2006 Java earthquake $\left(M_{w}=7.7\right)$, as recorded by ULN station (Ulaanbaatar, Mongolia), is shown in Figure 3. The moment magnitude $\left(M_{w}\right)$ value was derived from the calculation of Eq. (2) [20,21] after signal processing of the seismic moment was finished.

The radiated seismic energy $(E)$ is proportional to the energy flux of the seismic propagation from the source in the Earth's interior to the surface. The energy flux is the total seismic energy density measured at the high corner frequency. The formula is explained by Lomax, et al. [15] as follows:

$$
E=(1+q) \cdot 4 \pi r^{2}\left\{\frac{\left\langle F^{P}\right\rangle^{2}}{\left\langle F^{g P}\right\rangle^{2}}\right\} \cdot \rho \alpha \int v^{2}(t) d t
$$

where,

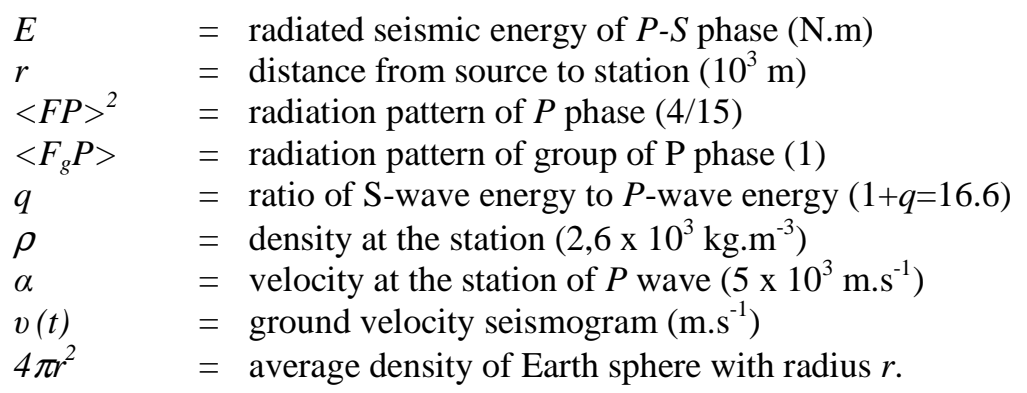

By substituting all constant parameters and Eq. (3), the equation becomes as follows:

$$
E=2.2 \times 10^{15} \cdot r^{2} \int v^{2}(t) d t
$$

The procedure of calculating energy is simpler than that of calculating seismic moment. The vertical ground velocity seismogram was used as the raw input data. A similar method was applied for cutting the phase of the $P-P P$ waves. The instrument response was removed by deconvolution using SAC. 


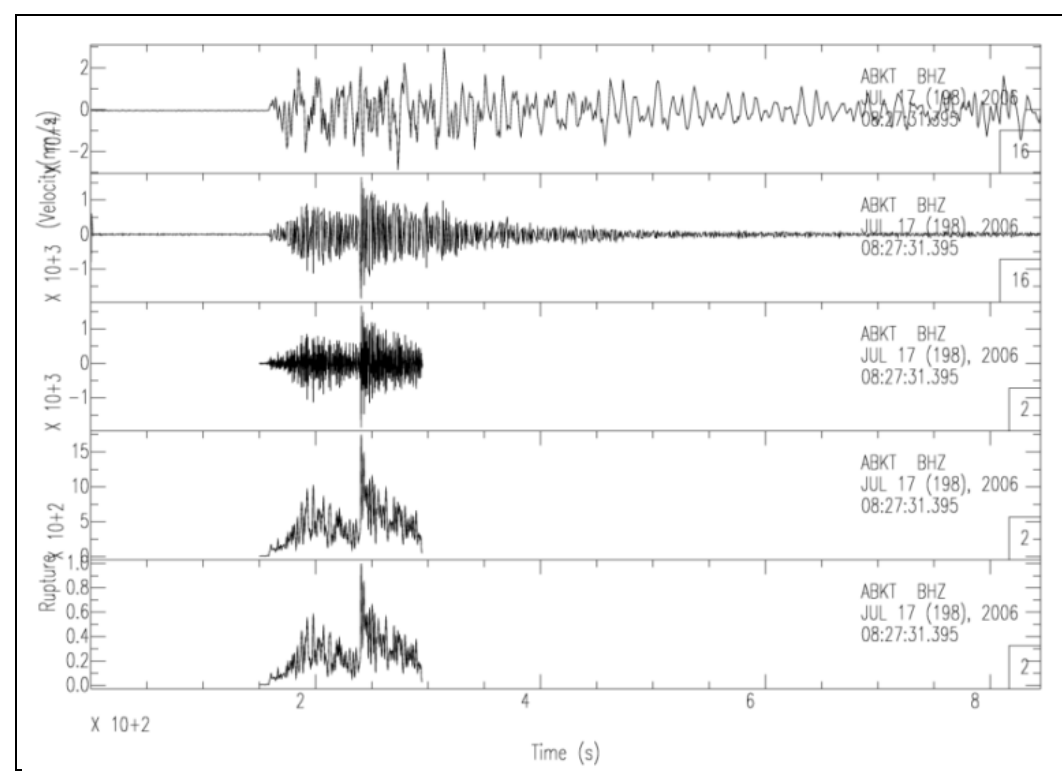

Figure 5 Procedure of rupture duration analysis by ABKT station for the July 17, 2006 Java earthquake. From top to bottom: velocity as the input data, removing instrument response and filtering, squaring, and normalized signal of rupture duration.

The Butterworth bandpass filter was applied with a frequency range between $0.001 \mathrm{~Hz}$ and $5 \mathrm{~Hz}$. Therefore, the velocity signal was squared before Eq. (4) was applied. For example, Figure 4 shows the case of the April 11, 2012 Sumatra earthquake, recorded at WAKE station (Wake Island, Pacific). Furthermore, the ratio $\Theta$ is a logarithmic relation between seismic energy and seismic moment [15],

$$
\Theta=\log \left(\frac{E}{M_{o}}\right)
$$

\section{$5 \quad$ Rupture Duration}

The rupture duration (To) is the time period that is required for an earthquake to occur, from the beginning to the end process of breaking along the fault area. The $P$ wave radiation has a high frequency and a high propagation velocity. Therefore, the signal can be isolated from the other wave phases in the seismogram. The size of the rupture duration is measured as the polynomial distribution area of $P$ wave ground motion by seismic wave analysis, referring to Lomax, et al. [15]. The procedure starts with taking the vertical component of the velocity signal from each station. The instrument response is removed 
before cutting the signal of the $P-S$ phase. In this study, the calculation of the rupture duration was employed for filtering, squaring, enveloping, and normalizing. We used the Butterworth bandpass filter with a high frequency range (between $1 \mathrm{~Hz}-2 \mathrm{~Hz}$ ). Then the velocity seismogram was modified by a squaring and enveloping procedure to obtain a squared velocity waveform with an amplitude that has a positive value. The signal of each station was normalized. Then all the normalized signals were stacked into one duration curve. Some stations with a high error and local-disturbance rate were removed. Figure 5 shows the procedure of rupture duration analysis at the ABKT station (Alibek, Turkmenistan).

Table 1 Earthquake-generated tsunamis in Indonesia (1991-2012).

\begin{tabular}{llllllll}
\hline \multicolumn{1}{c}{ Location } & Event & \multicolumn{1}{c}{ Ref. } & \multicolumn{1}{c}{$\boldsymbol{F}$} & $\boldsymbol{F M}$ & \multicolumn{1}{c}{$\boldsymbol{D}$} & $\boldsymbol{M}_{\boldsymbol{w}} \boldsymbol{G}$ & \multicolumn{1}{c}{ Lon/lat } \\
\hline Alor & 19910704 & L,G & NA & $T$ & 17 & 6.7 & $124.7 /-8.02$ \\
Flores & 19921212 & N,R,G,S & 26.2 & $T$ & 20.4 & 7.8 & $122.5 /-8.34$ \\
Java & 19940602 & N,R,G & 14 & $T$ & 15 & 7.8 & $113 /-11$ \\
Halmahera & 19941008 & R,G & NA & S & 15 & 6.8 & $127.8 / 1.2$ \\
Halmahera & 19950213 & L,R,G & NA & SO & 15 & 6.7 & $127.9 /-1.19$ \\
Timor & 19950514 & L,N,R,G & 4 & $T$ & 15.8 & 6.8 & $125.3 /-8.6$ \\
Minahasa & 19960101 & R,G & 3.4 & $T$ & 15 & 7.9 & $119.9 / 0.74$ \\
Papua & 19960217 & L,R,G & 7.7 & $T$ & 15 & 8.2 & $136.6 /-0.67$ \\
Sulawesi & 20000504 & R,G & NA & $S$ & 18.6 & 7.5 & $123.6 /-1.29$ \\
Sumatra & 20000604 & R,G & NA & $T$ & 33 & 7.8 & $101.9 /-4.73$ \\
Papua & 20021010 & R,G & NA & $T$ & 15 & 7.5 & $134.3 /-1.79$ \\
Sumatra & 20041226 & N,R,G & 50.9 & $T$ & 28.6 & 9.0 & $94.26 / 3.09$ \\
Sumatra & 20050328 & N,R,G & 3 & $T$ & 25.8 & 8.6 & $97.07 / 1.67$ \\
Sumatra & 20050410 & N,R,G & 0.4 & $T$ & 15 & 6.7 & $99.54 /-1.68$ \\
Ceram & 20060314 & N,R,G & NA & $T$ & 13 & 6.7 & $127.3 /-3.35$ \\
Java & 20060717 & N,R,G & 20.9 & $T$ & 20 & 7.7 & $107.8 /-10.3$ \\
Sumatra & 20070912 & N,R,G & 5 & $T$ & 24.4 & 8.5 & $101 /-3.78$ \\
Sumatra & 20080225 & N,G & 0.1 & $T$ & 14.4 & 7.2 & $99.95 /-2.66$ \\
Sulawesi & 20081116 & R,G & NA & $T$ & 29.2 & 7.3 & $122.1 / 1.5$ \\
Papua & 20090103 & R,G & NA & $T$ & 15.2 & 7.7 & $133.5 /-0.58$ \\
Talaud & 20090211 & R,G & 0.1 & $T$ & 23.9 & 7.1 & $126.8 / 3.92$ \\
Sumatra & 20090816 & N,R,G & 0.2 & $T$ & 12 & 6.7 & $99.45 /-1.56$ \\
Java & 20090902 & B & NA & $T$ & 53 & 7.0 & $107.3 /-8.12$ \\
Sumatra & 20090930 & N,R,G & 0.3 & $T O$ & 77.8 & 7.6 & $99.67 /-0.79$ \\
Sumatra & 20100406 & N,R,G & 0.4 & $T$ & 17.6 & 7.8 & $96.74 / 2.07$ \\
Sumatra & 20101025 & N,R,G & 7 & $T$ & 12 & 7.8 & $99.32 /-3.71$ \\
Sumatra & 20120411 & N,G & NA & $T O$ & 40 & 8.6 & $92.78 / 2.24$ \\
\hline
\end{tabular}

Remarks: Ref = reference, $\mathrm{L}=$ Latief, et al. [1], $\mathrm{S}=\mathrm{Shi}$, et al. [25], $\mathrm{N}=\mathrm{NOAA}, \mathrm{R}=\mathrm{Russia}, \mathrm{G}=$ Global CMT, B = BMKG, $H=$ tsunami height, NA = no available data, $F M=$ focal mechanism, $T$ = thrust fault, $S=$ strike-slip, $O=$ oblique, $D=\operatorname{depth}, M_{w} G=$ moment magnitude of Global CMT. 


\section{$6 \quad$ Results and Discussion}

The calculation results of $\mathrm{W}$ phase inversion, seismic moment, moment magnitude, seismic energy and rupture duration are shown in Table 2. The event locations are shown in Table 1. The epicenter coordinates, depth and focal mechanism (strike, dip, slip) resulted from the W phase method. Detailed information about earthquakes that generate tsunamis is useful for tsunami hazard zoning and additional information for the operational routine of InaTEWS at the Meteorological Climatological Geophysical Agency (BMKG). Currently, the criteria used to determine a potential local tsunami warning at InaTEWS are: magnitude $(M \geq 7.0$ Richter scale), depth $(D<100 \mathrm{~km})$ and epicenter in the sea (ocean) [26].

Table 2 Results of source parameters from W phase inversion \& signal analysis.

\begin{tabular}{llllllllll}
\hline \multicolumn{1}{c}{ Lon/lat } & Strke/dip/slip & $\boldsymbol{R} \boldsymbol{F C}$ & $\boldsymbol{H} \boldsymbol{T}$ & $\boldsymbol{M}_{\boldsymbol{w}}$ & $\boldsymbol{M}_{\boldsymbol{o}}$ & $\boldsymbol{E}$ & $\boldsymbol{\Theta}$ & $\boldsymbol{T o}$ & $\boldsymbol{C}$ \\
\hline $124.7 /-8.02$ & $97 / 38 / 135$ & 0.55 & 20 & 6.6 & 1.07 & 2.0 & -5.7 & 27 & $G$ \\
$122.3 /-8.74$ & $78 / 24 / 99$ & 0.85 & 30 & 7.7 & 52.48 & 229.1 & -5.4 & 85 & $L$ \\
$113.2 /-11.2$ & $269 / 7 / 85$ & 0.95 & -20 & 7.6 & 26.92 & 25.7 & -6.0 & 100 & $E$ \\
$127.9 /-1.59$ & $85 / 67 /-168$ & 0.92 & 20 & 6.6 & 1.12 & 4.2 & -5.4 & 27 & $G$ \\
$128 /-1.51$ & $86 / 46 /-3$ & 0.80 & 10 & 6.8 & 2.14 & 3.2 & -5.8 & 36 & $G$ \\
$125.3 /-8.6$ & $39 / 40 /-164$ & 0.10 & 20 & 6.7 & 1.32 & 3.0 & -5.6 & 58 & $G$ \\
$119.9 / 0.54$ & $31 / 8 / 50$ & 1.27 & 50 & 7.8 & 72.44 & 186.2 & -5.6 & 47 & $G$ \\
$136.2 /-0.87$ & $109 / 14 / 80$ & 1.37 & 50 & 8.0 & 144.54 & 457.1 & -5.5 & 117 & $G$ \\
$123.4 /-1.49$ & $230 / 75 /-173$ & 1.20 & -50 & 7.7 & 39.81 & 97.7 & -5.6 & 85 & $G$ \\
$102.1 /-4.72$ & $82 / 55 / 137$ & 0.81 & 110 & 7.8 & 72.44 & 562.3 & -5.1 & 85 & $G$ \\
$134.3 /-2.39$ & $65 / 76 /-43$ & 0.36 & 70 & 7.7 & 40.74 & 120.2 & -5.5 & 134 & $G$ \\
$94.26 / 2.89$ & $325 / 7 / 101$ & 0.90 & 50 & 9.0 & 3890.4 & 6309.6 & -5.8 & 257 & $G$ \\
$96.67 / 1.67$ & $332 / 10 / 114$ & 1.14 & 100 & 8.3 & 323.59 & 3981.1 & -4.9 & 100 & $G$ \\
$99.41 /-1.84$ & $151 / 27 / 103$ & 0.81 & 130 & 6.8 & 2.29 & 6.3 & -5.6 & 36 & $G$ \\
$127.2 /-3.6$ & $190 / 87 /-180$ & 0.59 & 50 & 6.8 & 2.00 & 6.3 & -5.5 & 117 & $G$ \\
$108.4 /-10.7$ & $275 / 12 / 77$ & 1.81 & -20 & 7.7 & 43.65 & 31.6 & -6.1 & 134 & $E$ \\
$101.4 /-4.4$ & $313 / 14 / 81$ & 1.61 & 160 & 8.2 & 263.03 & 2630.2 & -5.0 & 174 & $G$ \\
$99.55 /-2.86$ & $330 / 22 / 117$ & 1.00 & 120 & 7.3 & 10.47 & 33.9 & -5.5 & 47 & $G$ \\
$122.1 / 1.1$ & $58 / 14 / 90$ & 0.12 & 50 & 7.4 & 15.85 & 30.2 & -5.7 & 47 & $G$ \\
$132.8 /-0.78$ & $100 / 17 / 57$ & 0.81 & 50 & 7.8 & 70.79 & 154.9 & -5.7 & 36 & $G$ \\
$126.8 / 3.92$ & $173 / 37 / 81$ & 0.85 & 10 & 7.4 & 15.85 & 28.8 & -5.7 & 47 & $G$ \\
$99.05 /-1.76$ & $167 / 20 / 113$ & 0.82 & 90 & 6.7 & 1.55 & 3.0 & -5.7 & 36 & $G$ \\
$107.5 /-7.92$ & $118 / 83 / 92$ & 0.23 & 230 & 7.1 & 6.03 & 44.7 & -5.1 & 27 & $G$ \\
$99.87 /-0.99$ & $69 / 43 / 134$ & 1.11 & 120 & 7.8 & 57.54 & 141.3 & -5.6 & 27 & $G$ \\
$96.74 / 1.87$ & $307 / 9 / 86$ & 1.16 & 130 & 7.8 & 72.44 & 109.7 & -5.8 & 100 & $G$ \\
$98.89 /-3.88$ & $97 / 38 / 135$ & 1.24 & -5 & 7.6 & 35.48 & 50.1 & -5.8 & 117 & $E$ \\
$92.78 / 2.04$ & $78 / 24 / 99$ & 0.38 & -130 & 8.5 & 630.96 & 3311.3 & -5.3 & 134 & $G$ \\
\hline & & & & & & & & &
\end{tabular}

Remarks: $R F C=$ ratio of focal sphere comparison between Global CMT and $\mathrm{W}$ phase. $H T=$ hypocenter distance to trench $(\mathrm{km})$; a negative value means that the hypocenter is back at the beginning of trench. $M_{w}=$ moment magnitude of signal analysis, $M_{o}=$ seismic moment $\left(10^{19}\right.$ N.m), $E=$ seismic energy $\left(10^{13}\right.$ N.m $), \Theta=$ logarithmic ratio of seismic energy and moment, $T o=$ rupture duration (s), $C=$ character,$G=$ tsunamigenic earthquake, $E=$ tsunami earthquake, $L=$ landslide. 


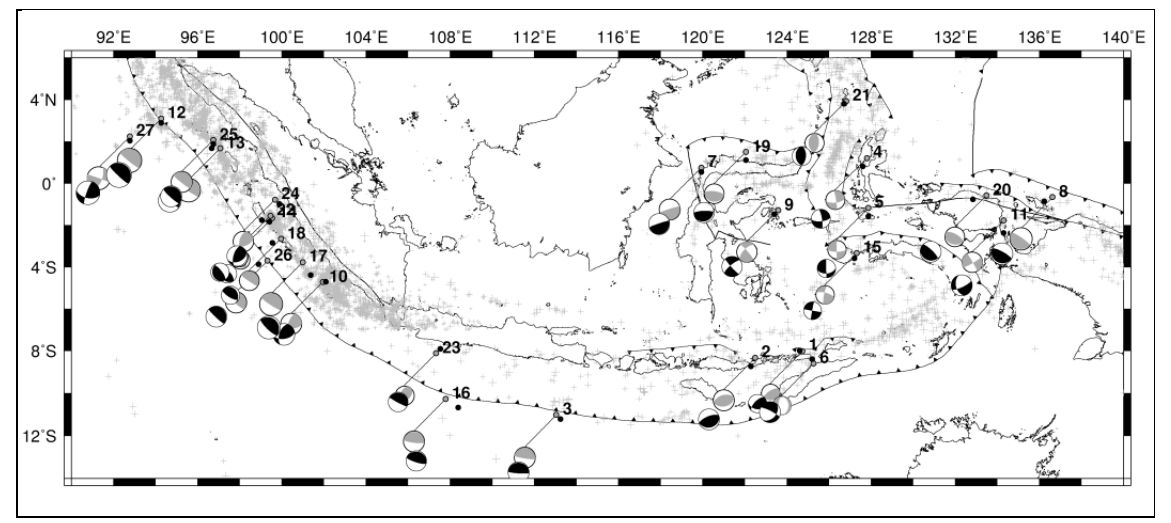

Figure 6 Earthquake and focal mechanism distributions in Indonesia. Earthquakes are shown as gray obelus, focal mechanism of $\mathrm{W}$ phase as black balls, and Global CMT as gray balls. Event numbers refer to Table 1.

InaTEWS plays a role in Asia and surrounding areas for detecting tele-tsunami. Therefore we recommend that Indonesia implement the source parameter retrieval of $\mathrm{W}$ phase, the ratio between seismic energy and seismic moment, and rupture duration. W phase has been adopted by the Japan Meteorological Agency (JMA), the Pacific Tsunami Warning Center (PTWC) and the United State of Geological Survey (USGS, http://www.usgs.gov) because it is consistent with both Global CMT and geological structure. Figure 6 and Table 2 show that our W phase analysis is similar to Global CMT. In general, strike, dip and slip of W phase are similar to those of Global CMT. Comparison of the values of the focal parameters between Global CMT and W phase are expressed by the ratio of focal sphere comparison $(R F C)$. This study has produced the consistent focal parameters as amount of 23 events ( $85 \%$ of total) with $R F C \geq$ 0.4 . However, there were four non-consistent events, with $R F C<0.4$ (no. 6, 11, 23 and 27). The focal mechanisms of the May 14, 1995 Timor earthquake (no. 6) and the October 10, 2002 Papua earthquake (no. 11) based on Global CMT were normal faults, whereas our results point to oblique-thrust faults. Compared to Global CMT for the September 2, 2009 Java earthquake (no. 23) and the April 11, 2012 Sumatra earthquake (no. 27), according to our results the focal spheres were in the opposite direction and slightly different. These nonconsistent results were caused by not reaching the minimum number of seismic stations. In addition, in the processing of the $\mathrm{W}$ phase, the three-component sensors were not used optimally in each station, except for one or two directions. The small number of sensors and large gaps in the distribution of the network also contributed to the poor results. 
The results of the source parameter determination by signal analysis are presented in Table 2. This study shows the value of radiated seismic energy to be $2.0 \times 10^{13} \mathrm{~N} . \mathrm{m} \leq E \leq 6.309 \times 10^{16} \mathrm{~N} . \mathrm{m}$, seismic moment $1.07 \times 10^{19} \mathrm{~N} . \mathrm{m} \leq$ $M_{o} \leq 3.89 \times 10^{22} \mathrm{~N} . \mathrm{m}$ and in accordance with moment magnitude $6.6 \leq M_{w} \leq$ 9.0. Overall, the value of the radiated seismic energy was lower than the seismic moment, although both describe the strength of the earthquakes with the same dimension of energy (Newton.meter). The difference is $1.0 \times 10^{6}$ times. This is caused by the flux of energy received at the station when attenuation effects occur [12]. The minimum energy flux is influenced by the low density of rocks in each receiving station and the low ground motion velocity. This situation causes the low value of the energy-moment ratio.

Our calculation of the seismic energy-moment ratio is different from Lomax, et al. [15], who divide the area of tsunamigenic earthquakes and tsunami earthquakes along a ratio line of $\Theta<-5.5$. The ratio line is derived from linear regression calculations on the distribution of the energy value moments of each earthquake. In this study, the threshold line is $\Theta=-5.8$, as shown in Figure 7. This distinction is based on a variety of data used by each researcher. Lomax, et al. [15] used inland and ocean large-scale earthquakes, inter-plate and intraplate earthquakes, and earthquakes that generated tsunamis. The epicenters that were used by Lomax, et al. [15] were from 34 events around the world, from 1992 to 2006 (15 years of observation). Our data focused only on earthquakes that generated tsunamis. The time range of this study is longer, i.e. from 1991 to 2012 (21 years of observation), covering 27 events. Furthermore, the energy calculations were influenced by the geometry of the distribution of the seismic waves as the energy passes through the layers of the earth's crust. Hence, they were also influenced by the distance from the source to the station and by the velocity of the seismic waves.

The rupture duration results of this study are shown in Figure 8. Tsunamigenic earthquakes are quite varied in $T o$ (> $10 \mathrm{~s}$ ) and $\log M_{o}$ (> 19 N.m.), that is from the shortest duration, such as the July 4, 1991 Timor earthquake (no. 1) with To $=27 \mathrm{~s}$, to the longest duration, such as the December 26, 2004 Sumatra earthquake (no. 12) with $T o=257 \mathrm{~s}$. The tsunami earthquake distribution ranged in rupture from $99 \mathrm{~s}<T o<135 \mathrm{~s}$ and in seismic moment from $20.4<$ $\log M_{o}<20.7$ N.m or with moderate seismic moment from $2.51 \times 10^{20}$ N.m $<$ $M_{o}<5.0 \times 10^{20} \mathrm{~N}$.m. These parameters are consistent with previous studies of tsunami earthquakes $[15,16]$. Generally, earthquake-generated tsunamis that are called tsunamigenic earthquakes, are characterized by a large moment magnitude $\left(M_{w} \geq 8\right)$, a long rupture duration, a high seismic energy and a large tsunami. 


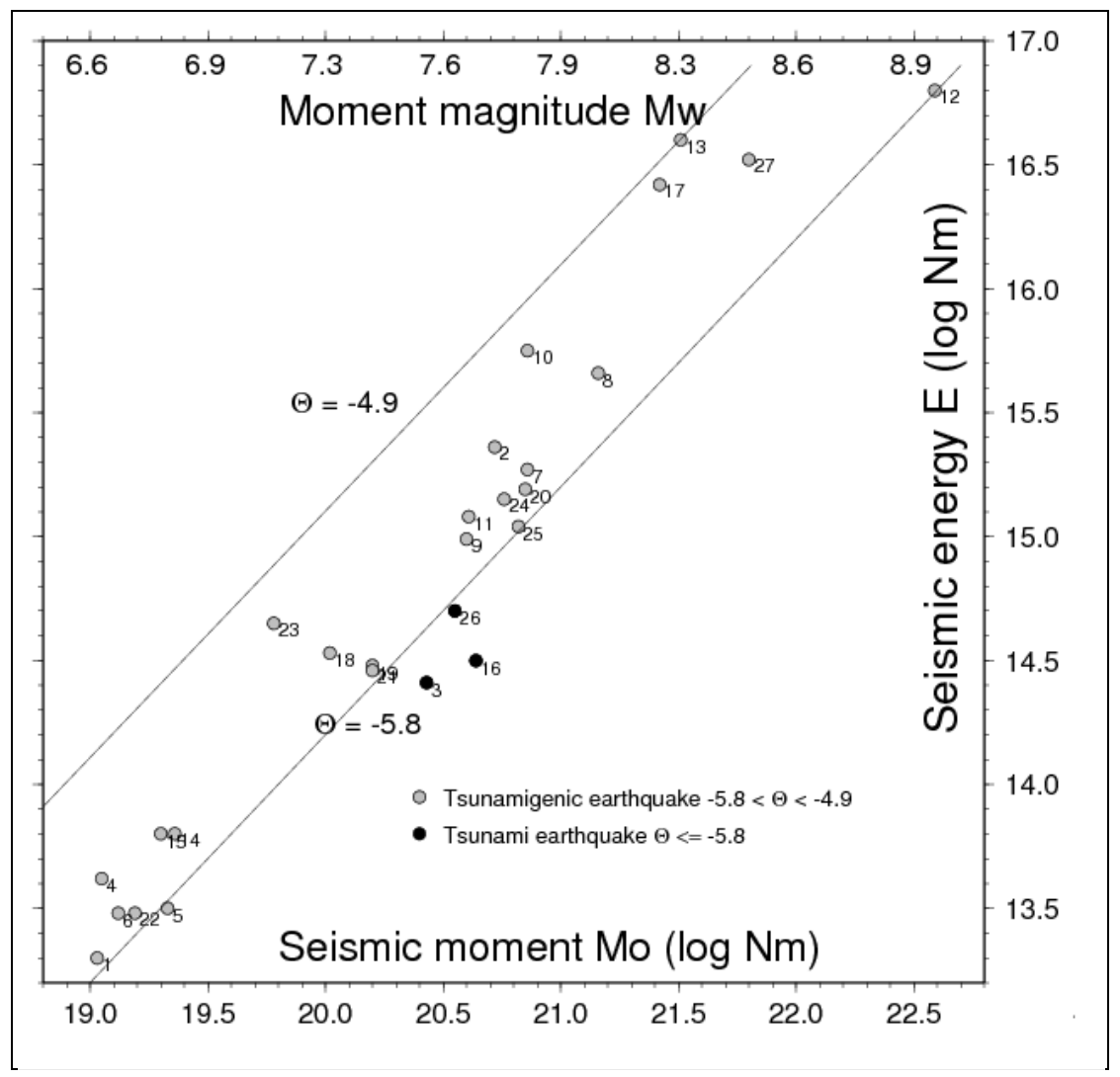

Figure 7 Ratio of energy-moment $(\Theta)$. The tsunamigenic earthquakes ranged between $-5.8<\Theta<-4.9$ while the tsunami earthquakes had $\Theta \leq-5.8$.

Specific earthquake-generated tsunamis, called tsunami earthquakes, are characterized by a medium moment magnitude $\left(M_{w}<8\right)$, a long rupture duration, a low seismic energy but a large tsunami. This is caused by the fact that the epicenter occurs in the segment of the displacement rocks between the plates in the area of the accretionary wedge with unstable material conditions. This area has a weak rigidity where brittle sedimentary and fragile rocks are mixed. This condition causes a weakening of the seismic radiation energy and a long rupture duration [27].

Conversely, some tsunamigenic earthquakes with a moderate moment magnitude only generate a very small tsunami. This is caused by a large focal depth, a long distance from the hypocenter to the trench and a horizontal focal mechanism. 


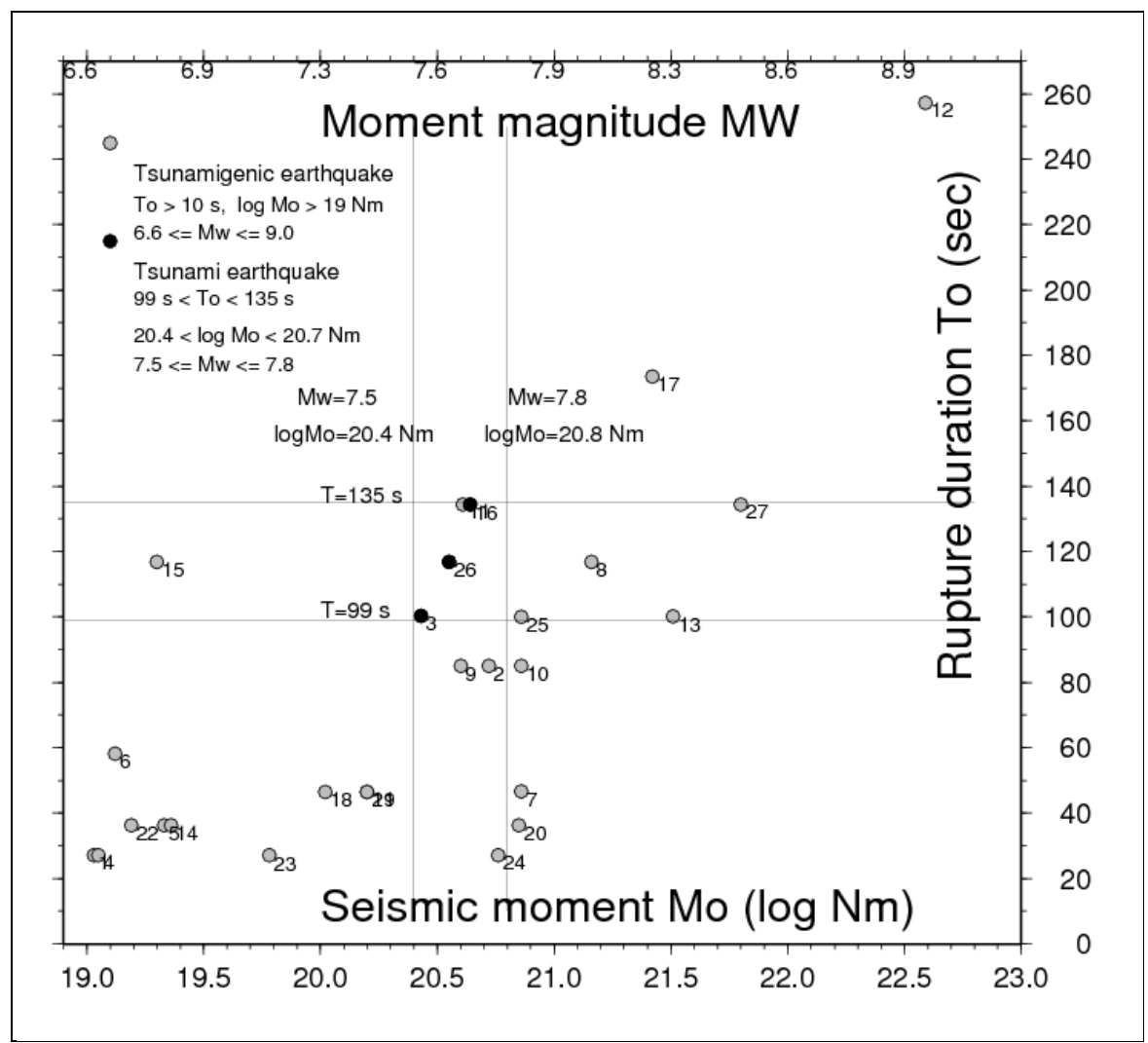

Figure 8 Ratio of seismic moment-rupture duration. The tsunami earthquakes ranged in rupture from $99 \mathrm{~s}<T o<135 \mathrm{~s}$, in seismic moment from $20.4<\log M_{o}$ $<20.7$ N.m and $7.5 \leq M_{w} \leq 7.8$. Tsunamigenic earthquakes had $T o>10 \mathrm{~s}$ and $\log$ Mo $>19$ N.m.

An example is the September 30, 2009 Sumatra earthquake (no. 24), which had a moderate magnitude $\left(M_{w}=7.6\right)$ and very shallow focal depth $(D=24.4 \mathrm{~km})$, but was located nearby a narrow fore-arc basin with minimum seawater volume. Therefore it only caused a very small tsunami $(H=0.3 \mathrm{~m})$. The March 14, 2006 Ceram earthquake (no. 15$)$ had a long rupture duration $(T o=117 \mathrm{~s})$, a very low seismic moment $\left(M_{o}=2.0 \times 10^{19} \mathrm{~N} . \mathrm{m}\right)$, a smaller than moderate magnitude $\left(M_{w}\right.$ = 6.7), but had a long distance from the hypocenter to the trench. As a consequence, it did not cause a tsunami.

We conclude that tsunami earthquakes are a special category of tsunamigenic earthquakes. From the discussion of the source parameters, such as the rupture duration, the seismic moment and the ratio of energy-seismic moment, the 
unique character of tsunami earthquakes could be established. In addition, there were the focal depth and the distance from trench. The 2 June 1994 Java earthquake (no. 3) had a very shallow depth $(D=15 \mathrm{~km})$, a very small distance from the hypocenter to the trench, a moderate magnitude $\left(M_{w}=7.8\right)$ but a very large tsunami height $(H=14 \mathrm{~m})$. This is consistent with tsunami earthquake characteristics in previous studies [28]. The July 17, 2006 Java earthquake (no. 16) also had a very shallow depth $(D=20 \mathrm{~km})$ and a very small distance from the hypocenter to the trench (Sunda Trench). The slip direction was distributed near the surface with a shallow depth, which is a characteristic of tsunami earthquakes [29]. The October 25, 2010 Sumatra earthquake (no. 26) had a very shallow depth $(D=12 \mathrm{~km})$ and was located near the trench and the accretionary wedge. These parameters are similar to the ones from previous studies and categorize it as a tsunami earthquake [15].

From the epicenter determined by $\mathrm{W}$ phase, we can estimate the distance between the hypocenter and the trench. Subsequently, we can draw a crosssectional line for some events that are perpendicular to the trench lines, as shown in Figure 9. For the North Sumatra region, the December 26, 2004 Sumatra earthquake (no. 12) and the April 11, 2012 Sumatra earthquake (no. 27) located at the front of the trench $(H T=50 \mathrm{~km})$ and the back of the trench $(H T=-130 \mathrm{~km})$. In this study, the tsunamigenic earthquake events had a short to long hypocenter distance to the trench $(10 \mathrm{~km}<H T \leq 230 \mathrm{~km})$ and a shallow focal depth $(12 \mathrm{~km} \leq D \leq 77.8 \mathrm{~km})$. The tsunami earthquakes had a very small distance from the hypocenter to the trench $(H T \leq 20 \mathrm{~km})$ and very shallow depth $(D \leq 20 \mathrm{~km})$.

The December 12, 1992 Flores earthquake (no. 2) caused a large tsunami (26.2 $\mathrm{m})$ but had a medium magnitude $\left(M_{w}=7.8\right)$. The epicenter was very close to the offshore of Maumere $(H T=50 \mathrm{~km})$. The earthquake was related to the back-arc thrust fault and increased marine erosion, after which an extensive landslide took place. The survey observations showed as evidence the fractured cliff near Riang-Kroko, watermarks on wall structures, scattered coral boulders, and tree leaves. The event was characterized as a landslide tsunami [24,30]. Beside that, the five times reflected tsunami waves hit the island and its surroundings and caused 2,080 people to be killed [24].

\section{Conclusions}

We have characterized earthquake-generated tsunamis that occurred in Indonesia from 1991 to 2012. This characterization was based on a source parameter analysis of the focal mechanism retrieved from the $\mathrm{W}$ phase, the ratio of seismic energy and seismic moment, the moment magnitude, the rupture duration and the distance of the hypocenter to the trench. The results of this 
study make it possible to differentiate two kinds of earthquake-generated tsunamis: tsunamigenic earthquakes and tsunami earthquakes.

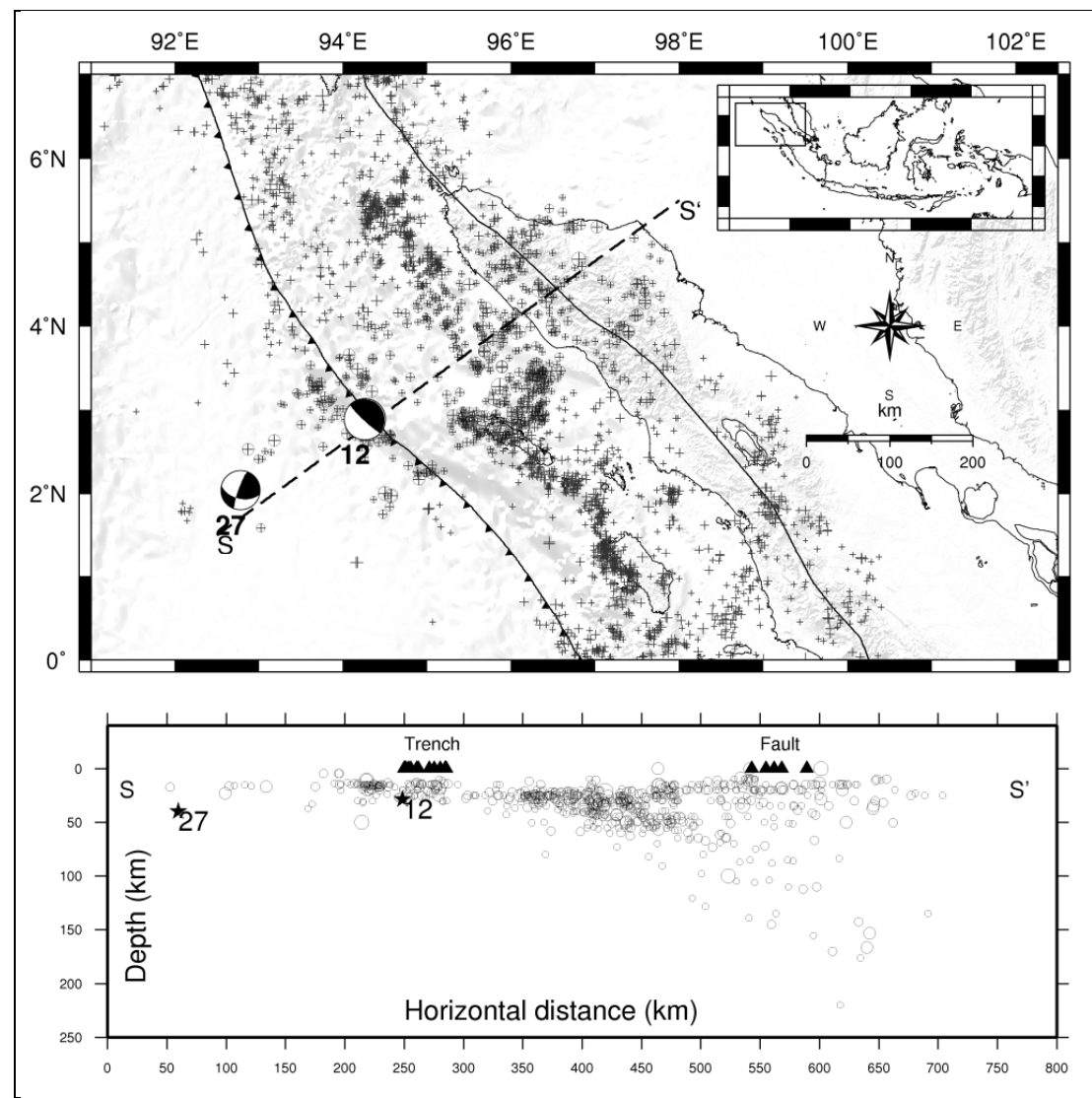

Figure 9 Seismic distribution in the North Sumatra region, with the December 26, 2004 (no. 12) and the April 11, 2012 Sumatra earthquake (no. 27). Top: Mercator map with SS' projection line. Earthquakes are shown as gray obelus, the projected earthquakes as black circles, the focal mechanisms of W phase as black balls. Bottom: cross-sectional map. Projected focal mechanisms shown as black stars, trenches and faults as black triangles.

Most of the earthquakes, 24 events, were tsunamigenic earthquakes. They were characterized by various types of fault mechanisms, a low ratio of seismic energy and seismic moment, a short to long rupture duration, a short to long distance from the hypocenter to the trench, a shallow focal depth, a small to large magnitude, and a small to large tsunami height. 
The remaining three events were tsunami earthquakes. These were the June 2, 1994 Java earthquake, the July 17, 2006 Java earthquake and the October 25, 2010 Sumatra earthquake. The characteristics of these tsunami earthquakes were: thrust fault mechanism only, a very low ratio of seismic energy and seismic moment, a long rupture duration, only a short distance from the hypocenter to the trench, a very shallow focal depth, a moderate magnitude but always a large tsunami height.

\section{Acknowledgements}

The authors would like to express their gratitude and appreciation to Prof. Kenji Satake of Earthquake Research Institute (ERI), University of Tokyo, Japan and Prof. Luis Rivera of École et Observatoire des Sciences de la Terre, Louis Pasteur University, for basic idea and technical assistance. We thank the anonymous reviewers for their comments and suggestions. We thank BMKG and ITB for funding this study within the framework of their PhD program. This work was carried out using GMT, SAC, IRIS, hypocenter data of Engdahl, Global CMT and GEBCO.

\section{References}

[1] Latief, H., Puspito, N.T. \& Imamura, Tsunami Catalog and Zones in Indonesia, J. Nat. Dis. Science, 22(1), Japan, 2000.

[2] Puspito, N.T., Statistical Data of Tsunamigenic Earthquakes in the Indonesian Region, International Symposium on Earthquake and Precursor Proceeding, Puslitbang BMKG, Bukit Tinggi, 2009.

[3] Fujii, Y. \& Satake, K., Source of the July 2006 West Java Tsunami Estimated from Tide Gauge Records, Geophys. Res. Lett., 33, L24317, doi: 10.1029/2006GL028049, 2006.

[4] Convers, J.A. \& Newman, A.V., Global Evaluation of Large Earthquake from 1997 Through Mid-2010, J. Geophys. Res., 116, B08304, 2011.

[5] Ammon, C.J., Ji, C., Thio, H.K., Robinson, D., Ni, S., Hjorleifdottir, V., Kanamori, H., Lay, T., Das, S., Helmberger, D., Ichinose, G., Polet, J. \& Wald, D., Rupture Process of the 2004 Sumatra-Andaman Earthquake, Science, 308, 2005.

[6] Ammon, C.J., Kanamori, H., Lay, T. \& Velasco, A.A., The July 2006 Java Tsunami Earthquake, Geophys. Res. Lett., 33, L24308, doi: 10.1029/2006GL028005, 2006.

[7] Satake, K. \& Tanioka, Y., Sources of Tsunami and Tsunamigenic Earthquakes in Subduction Zones, Pure Appl. Geophys., 154, pp. 467483, 0033-4553:99:040467-17, 1999.

[8] Kanamori, H., Mechanism of Tsunami Earthquakes, Phys. Earth Planet. Inter., 11, pp. 312-332, 1972. 
[9] Polet, J., \& Kanamori, H., Tsunami Earthquakes, Encyclopedia of Complexity and Systems Science, Springer-Verlag 2009, Robert A. Meyers, 10.1007/978-0-387-30440-3_567, 2009.

[10] Kanamori, H., W Phase, Geophys. Res. Lett., 20(16), pp. 1691-1694, 1993.

[11] Kanamori, H. \& Rivera, L., Source Inversion of W-phase, Speeding Up Seismic Tsunami Warning, Geophys. J. Int., 175, pp. 222-238, doi: 10.1111/j.1365-246X.2008.03887.x, 2008.

[12] Handayani, T., W-Phase Analysis for Tsunami Warning, Master Thesis, National Graduate Institute for Policy Studies, Tokyo, Japan, Building Research Institute, Tsukuba, Japan, MEE08175, Disaster Management Policy Program, 2009.

[13] Newman, A. \& Okal, E., Teleseismic Estimates of Radiated Seismic Energy: The E/M Discriminant for Tsunami Earthquakes, Journal of Geophysical Research, 103(B11), doi: 10.1029/98JB02236, ISSN: 01480227, 1998.

[14] Polet, J. \& Kanamori, H., Shallow Subduction Zone Earthquake, Geophys. J. Int., 142, pp. 684-702, 2000.

[15] Lomax, A., Michelini, A. \& Piatanesi, A., An Energy-Duration Procedure for Rapid Determination of Earthquake Magnitude and Tsunamigenic Potential, Geophys. J. Int., 170, pp. 1195-1209, doi:10.1111/j.1365-246X.2007.03469.x, 2007.

[16] Newman, A., Hayes, G., Wei, Y. \& Convers, J., The 25 October 2010 Sumatra Tsunami Earthquake from Real-Time Discriminants, Geophys. Res. Lett., 38, L05302, doi: 10.1029/2010GL046498, 2011.

[17] Engdahl, E.R., van der Hilst, R. \& Buland, R., Global Teleseismic Earthquake Relocation with Improved Travel Times and Procedures for Depth Determination, Bull. Seism. Soc. Am., 88, pp. 722-743, 1998.

[18] Hayes, G.P., Rivera, L. \& Kanamori, H., Source Inversion of the WPhase: Realtime Implementation and Extension to Low Magnitudes, Seism. Res. Lett., 80(5), doi: 10.1785/gssrl.80.5.817, 2009.

[19] Boatwright, J. \& Choy, G., Teleseismic Estimates of Energy Radiated by Shallow Earthquake, J. Geophys. Res., 91(B2), pp. 2095-2112, 1986.

[20] Kanamori, H., The Energy Release in Great Earthquake, J. Geophys. Res., 82, pp. 2981-2987, 1977.

[21] Tsuboi, S., Abe, K., Takano, K. \& Yamanaka, Y., Rapid Determination of $M_{w}$ from Broadband $P$ Waveforms, Bull. Seism. Soc. Am., 83, pp. 606613, 1995.

[22] Crotwell, H.P., Owens, T.J. \& Ritsema, J., The Tau-P toolkit, Flexible Seismik Travel-Time \& Ray-Path Utilities, Seism. Res. Lett., 70, pp. 154160, 1999.

[23] Bormann, P., Engdahl, B. \& Kind, R., Seismic Wave Propagation and Earth models, New Manual of Seismology Observatory Practice 
(NMSOP-2), IASPEI, GFZ German Research Center for Geosciences, DOI: 10.2312/GFZ.NMSOP-2, pp.47-57, 2002.

[24] Goldstein, P. \& Snoke, A., SAC Availability for the IRIS Community, http://www.iris.edu/dms/newsletter/vol7/no1/sac-availability-for-the-iriscommunity, March 2005 (8 March 2013).

[25] Shi, S., Dawson, A.G. \& Smith, D.E., Geomorphological Impact of The Flores Tsunami of 12th December 1992, Tsuchiya, Y. \& Shuto, N., Tsunami: Progress in Prediction, Disaster Prevention and Warning, Kluwer Academic Publishers, Netherlands, pp. 187-195, 1995.

[26] BMKG (Badan Meteorologi Klimatologi dan Geofisika), Panduan Peringatan Dini Tsunami, BMKG (unpublished), pp. 7-35, 2010.

[27] Bilek, S.L. \& Lay, T., Tsunami Earthquake Possibly Widespread Manifestation, Geophys. Res. Lett., 29(14), 10.1029/2002GL015215, 2002.

[28] Synolakis C., Imamura, F., Tsuji, Y., Matsutomi, H., Tinti, S., Cook, B., Chandra, Y.P. \& Usman, M., Damage, Conditions of Java Tsunami of 1994 Analyzed, EOS, Trans. Am. Geoph. Union, 76(26), pp. 257-264, 1995.

[29] Kanamori, H. \& Brodsky, E.E., The Physics of Earthquake, Institute of Physics Publishing, Rep. Prog. Phys., 67, pp. 1429-1496, 2004.

[30] Kawata, Y., Tsuji, Y., Syamsudin, A.R., Sunarjo, Matsuyama, M., Matsutomi, H., Imamura, F. \& Takahashi, T., Response of Residents at The Moment of Tsunami-The 1992 Flores Island Earthquake Tsunami, Indonesia, Tsuchiya, Y. \& Shuto, N., Tsunami: Progress in Prediction, Disaster Prevention and Warning, Kluwer Academic Publishers, Netherlands, pp. 173-185, 1995. 